as variable of high disease activity state showed the following: for ASDAS-CRP, ASDAS-ESR and BASDAl the AUCs (area under curve) were 0.89 ( $\mathrm{P}=0.05 ; 95 \%$ $\mathrm{Cl} 0.80-0.99), 0.88(\mathrm{P}<0.001 ; 95 \% \mathrm{Cl} 0.77-0.99)$, and $0.99(\mathrm{P}=0.009 ; 95 \% \mathrm{Cl}$ $0.97-1.00$ ).For CRP and ESR the AUCs were 0.81 and 0.79 . This shows the high accuracy of the three scores in assessing SpA activity,but with a lower fidelity of the inflammatory markers alone.When dividing patients according to BASDAl score, $14 \%$ showed a more active disease than the rest of $86 \%$ who had low disease activity.Mean ASDAS-CRP scores in the first group was 3.31. When correlating disease activity scores for the entire study group we observed that BASDAl correlated to both ASDAS scores $(r=0.65$ and $0.71, P<0.001)$ and that PtGA showed a stronger correlation to BASDAI $(r=0.912, P<0.01)$ than ASDAS and to acute phase reactants.

Conclusions: This study shows that disease activity scores have good discriminatory powers. BASDAI surpassed ASDAS scores when relating to the PtGA. According to Van der Heijde et al.(1), the only situation in which BASDAI can outperform ASDAS is when assessing the PASS (patient acceptable symptom state). However, ASDAS-CRP had better discriminatory power than ASDAS-ESR or acute phase reactants. This demonstrates that ASDAS-CRP is a more objective evaluation that can better differentiate patients with high or low disease activity. References:

[1] D van der Heijde,ASDAS, a highly discriminatory ASAS-endorsed disease activity score in patients with ankylosing spondylitis, Ann. Rheum. Dis,vol. 68,Dec 2009.

Disclosure of Interest: None declared

DOI: 10.1136/annrheumdis-2017-eular.5326

\section{THU0666 PATIENT GLOBAL ASSESSMENT IS MORE SENSITIVE TO CHANGE THAN HEALTH-RELATED QUALITY OF LIFE INSTRUMENTS IN EARLY AXIAL SPONDYLOARTHRITIS OVER 3 YEARS: DATA FROM THE DESIR COHORT}

D. Puyraimond-Zemmour ${ }^{1,2}$, C. Desthieux ${ }^{1,2}$, A. Ruyssen-Witrand ${ }^{3}$

B. Fautrel ${ }^{1,2}$, L. Gossec ${ }^{1,2}$. ${ }^{1}$ Pitie Salpetriere Hospital; ${ }^{2}$ Paris 06 university, Pierre and Marie Curie, Paris: ${ }^{3} \mathrm{CHU}$ de Toulouse, Hôpital Pierre-Paul Riquet, Toulouse, France

Background: Several questionnaires assess similar constructs of global patientreported state or Health-Related Quality of Life (HRQoL).

Objectives: To evaluate sensitivity to change (ie, discriminance) of several questionnaires in early axial spondyloarthritis (axSpA) over 3 years of follow up: the SF36, axial spondyloarthritis quality of life (ASQoL), axial spondyloarthritis health assessment questionnaire (AS-HAQ) and patient global assessment (PGA).

Methods: DESIR is an ongoing prospective, multicenter, longitudinal, observational French cohort (1). Patients had inflammatory back pain of more than 3 months and less than 3 years suggestive of axSpA. For our analysis, only patients with no missing data for MCS and PCS SF36 values during the first 3 years were included. A global construct of patient global state was assessed by the SF36 questionnaire and its 2 subscales (scored 0-100 with higher scores indicating better status): the physical composite score (PCS) and the mental composite score (MCS), AsQoL, a disease-specific HRQoL scale, PGA and AS-HAQ. ASDAS-CRP was used as comparator. Each outcome was assessed at baseline, 6 months, 12 months, 24 months and 36 months. Standardized mean differences (SMD) were calculated using Cohen's effect size with confidence intervals, between each time point for each outcome. A SMD $<0.5$ is usually considered small, between 0.5 and 0.8 moderate and $>0.8$ as important.

Results: In all, 442 patients were analyzed: at baseline, mean age was $34.2 \pm 8.6$ years; mean disease duration was $18.6 \pm 10.7$ months; $239(54 \%)$ were females, $274(62 \%)$ had HLAB27 and 124 (28\%) had radiological sacroiliitis. At baseline, patients were not in an optimal state; improvement was clear up to month 6 then minimal (at the group level): Table. Sensitivity to change was greatest for PGA, then ASQoL whereas AS-HAQ, MCS and PCS appeared the least discriminant measure (Table).

Conclusions: PGA was more sensitive to change than HRQoL measures in early
axSpA. ASDAS appeared also sensitive to change. Changes in all the measures were very small at the group level after 6 months of follow-up indicating the concepts convered may be as much patient- as disease-related.

\section{cerences:}

[1] Dougados M. et al. Clinical presentation of patients suffering from recent onset chronic inflammatory back pain suggestive of spondyloarthritis: The DESIR cohort.Joint Bone Spine. 2015;82(5):345-51.

Disclosure of Interest: None declared

DOI: 10.1136/annrheumdis-2017-eular.4866

\section{THU0667 A QUALITATIVE AND QUANTITATIVE COMPARISON OF SYNOVIAL BIOPSY TECHNIQUES DURING CLINICAL TRIALS OF INFLAMMATORY ARTHRITIS}

F. Humby ${ }^{1}$, S. Bugatti ${ }^{2}$, A. Filer ${ }^{3}$, S. Kelly ${ }^{4}$, A. Manzo ${ }^{2}$, E. Souza ${ }^{5}$, V. Romao ${ }^{5}$ V. Rocher ${ }^{1}$, R. Hands ${ }^{1}$, M. Wechalekar ${ }^{6}$, J. Fonseca ${ }^{5}$, C. Montecucco ${ }^{2}$,

C. Pitzalis ${ }^{1} .{ }^{1}$ Experimental Medicine and Rheumatology, Barts and the London School of Medicine and Dentistry, London, United Kingdom; ${ }^{2}$ Division of Rheumatology, University of Pavia, Pavia, Italy; ${ }^{3}$ Institute of Inflammation and Ageing, University of Birmingham, Birmingham; ${ }^{4}$ Department of Rheumatology, Barts Health NHS Trust, London, United Kingdom; ${ }^{5}$ Department of

Rheumatology, Lisbon Academic Medical Centre, Lisbon, Portugal;

${ }^{6}$ Rheumatology Unit, Repatriation General Hospital, Adelaide, Australia

Background: Synovial tissue is an attractive area of research for biomarkers of disease outcome in RA. Currently acquisition of synovial tissue using an arthroscopic approach in clinical trials is recommended though two US-guided techniques have been described, a portal and forceps (P\&F) approach and an adaptation using a quick core needle (NB). However before US-guided biopsy techniques are widely adopted into clinical trials validation of performance against arthroscopy is required.

Objectives: To evaluate whether there were significant differences in synovial sampling quality and quantity between arthroscopic, US-P\&F and US-NB procedures within the context of clinical trials.

Methods: This was a multicentre retrospective analysis of inflammatory arthritis patients recruited to clinical trials utilizing US-guided NB (Barts Health NHS Trust), US-guided P\&F (ICRSS Policlinico San Matteo and University Hospital Birmingham) and arthroscopic biopsy (Repatriation General Hospital).

Paraffin embedded synovial sections from each procedure underwent $\mathrm{H} \& \mathrm{E}$ staining and sections examined for intact cell lining layer (graded sections) Biopsy procedures were segregated into large (knee) and small joint procedures (wrist/MCP) for analysis. Proportion of samples yielding graded tissue per procedure was recorded. Using CellSens Dimensions software the mean area of synovial tissue obtained per procedure was determined. In addition the degree of synovitis was assessed using semi-quantitiative scoring (0-9).

Results: 78 patient procedures were evaluated, 22 on small joints (11 US-NB, 11 US P\&F) and 56 on large joints (11 US-NB, 35 US-P\&F, 10 arthroscopic). 47 patients had RA, 11 undifferentiated arthritis and 10 psoriatic arthritis. Arthroscopic sampling resulted in a significantly higher area of tissue retrieved per procedure than US P\&F or US-NB. There were no significant differences in proportion of graded samples per procedure suggesting quality of synovial tissue was preserved between techniques. Finally no significant differences in degree of histological synovitis were demonstrated between sampling techniques.

Conclusions: The results suggest that US-guided biopsy provides a reliable method for sampling synovial tissue of comparable quality to that obtained from arthroscopy. However when sampling large joints arthroscopic techniques, and when sampling small joints US-P\&F yield a significantly higher quantity, though not quality, of tissue per procedure than US-NB. These results may influence choice of biopsy technique when designing clinical trial protocols in inflammatory arthritis.

Disclosure of Interest: None declared

DOI: 10.1136/annrheumdis-2017-eular.1918

Abstract THU0666 - Table 1. Sensitivity to change (SMD (95\% CI]) of different outcomes in early axSpA over 3 years

\begin{tabular}{|c|c|c|c|c|c|}
\hline & $\begin{array}{c}\text { Baseline value } \\
\text { (mean } \pm \text { SD) }\end{array}$ & $\begin{array}{l}\text { SMD between baseline and M6 } \\
{[95 \% \text { confidence interval }(\mathrm{Cl})]}\end{array}$ & $\begin{array}{c}\text { SMD between M6 and M12 } \\
{[95 \% \mathrm{Cl}]}\end{array}$ & $\begin{array}{c}\text { SMD between M12 and M24 } \\
{[95 \% \mathrm{Cl}]}\end{array}$ & $\begin{array}{c}\text { SMD between M24 and M36 } \\
{[95 \% \mathrm{Cl}]}\end{array}$ \\
\hline PCS & $40.5 \pm 9.2$ & $0.27[-0.41 ;-0.14]$ & $0.02[-0.11 ; 0.15]$ & $0.02[-0.11 ; 0.16]$ & $-0.02[-0.15 ; 0.11]$ \\
\hline MCS & $40.4 \pm 11.0$ & $-0,26[-0,39 ;-0,13]$ & $0.02[-0.11 ; 0.16]$ & $-0.08[-0.21 ; 0.05]$ & $0.00[-0.13 ; 0.13]$ \\
\hline PGA & $6.1 \pm 2.2$ & 0.69 [0.56;0.83], & $0.09[-0.04 ; 0.22]$ & $0.06[-0.07 ; 0.19]$ & $0.05[-0.08 ; 0.18]$ \\
\hline ASQoL & $9.1 \pm 5$ & $0.36[0.22 ; 0.49]$ & $-0.01[-0.14 ; 0.12]$ & $0.02[-0.12 ; 0.15]$ & $0.00[-0.14 ; 0.13]$ \\
\hline AS-HAQ & $0.63 \pm 0.5$ & 0.24 [0.11;0.38], & $-0.04[-0.17 ; 0.09]$ & $0.02[-0.11 ; 0.15]$ & $0.00[-0.13 ; 0.13]$ \\
\hline ASDAS-CRP & $2.6 \pm 0.98$ & $0.52[0.38 ; 0.65]$. & $-0.03[-0.17 ; 0.10]$ & $0.06[-0.08 ; 0.20]$ & $0.10[-0.04 ; 0.24]$ \\
\hline
\end{tabular}

Abstract THU0667 - Table 1

\begin{tabular}{|c|c|c|c|c|c|c|c|}
\hline \multirow[t]{2}{*}{ Mean (SD) } & \multicolumn{3}{|c|}{ Small joint biopsies } & \multirow[b]{2}{*}{ US-NB $(n=11)$} & \multicolumn{2}{|c|}{ Large joint biopsies } & \multirow[b]{2}{*}{$P$ value } \\
\hline & US -NB $(n=11)$ & US P\&F $(n=11)$ & $P$ value & & US P\&F ( $n=35)$ & Arthroscopic $(n=10)$ & \\
\hline Joint biopsied & $\begin{array}{l}7 \text { wrist } \\
5 \mathrm{MCP}\end{array}$ & $\begin{array}{c}1 \text { wrist } \\
10 \mathrm{MCP}\end{array}$ & & 10 knee & $\begin{array}{c}32 \text { knee } \\
3 \text { ankle }\end{array}$ & 10 knee & \\
\hline$\%$ graded samples per procedure & $82.3(22.4)$ & $91(10)$ & 0.34 & $89.8(17.5)$ & $83.23(19)$ & $97(11)$ & 0.08 \\
\hline Mean area of tissue $\left(\mathrm{mm}^{2}\right)$ per procedure & $3.19(1.75)$ & $7.95(4.91)$ & $<0.005^{\star}$ & $4.66(3.19)$ & $8.8(8.17)$ & $17.64(7.56)$ & $<0.0001^{*}$ \\
\hline Synovitis score & $4.9(3.2)$ & NA & NA & $3.8(2.6)$ & $4.53(2.26)$ & $4.5(1.71)$ & 0.35 \\
\hline
\end{tabular}

